
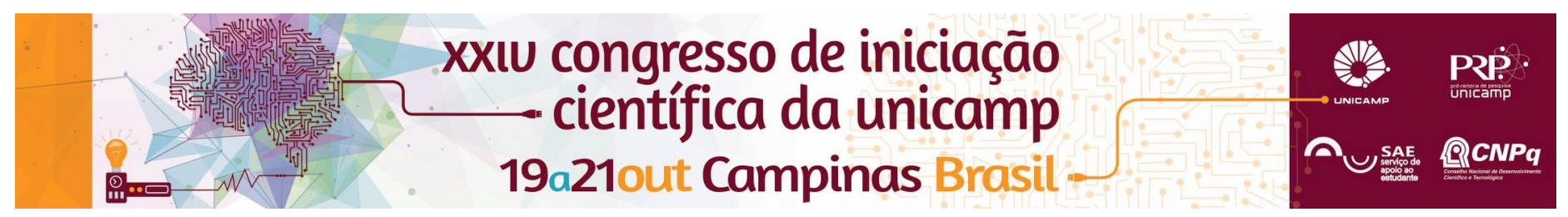

\title{
Práticas Curriculares e Disciplinas Escolares: uma cartografia da produção acadêmica brasileira
}

\section{Juliana Cristina Silva*, Maria Inês Petrucci-Rosa.}

\section{Resumo}

O projeto de pesquisa identifica e analisa as tendências teórico-metodológicas na produção acadêmica, no que tange à temática identidade docente e disciplina escolar, por meio da construção de um banco de dados. Metodologicamente baseamos no Portal de Periódicos da Capes (conteúdo assinado pela Unicamp). Primeiramente realizamos um levantamento bibliográfico, em que identificamos setenta produções. Em segunda etapa elaboramos resumos (modelo tipo REDUC) dos trabalhos selecionados no levantamento bibliográfico e, por fim identificamos e delimitamos as tendências teórico-metodológicas presentes neles.

Palavras-chave:

Identidade docente, disciplina escolar, banco de dados.

\section{Introdução}

O projeto de pesquisa teve por objetivos: 1. proporcionar uma experiência de formação de iniciação científica a partir da competência básica de realizar levantamentos bibliográficos; 2 . ampliar a compreensão sobre a produção acadêmica na temática em questão; 3 . subsidiar os projetos coordenados pela orientadora que investigam relações entre identidade docente e a natureza da disciplina escolar.

Elaboramos um banco de dados das produções acadêmicas, no que tange à temática identidade docente e disciplina escolar. Metodologicamente utilizamos como base de busca o Portal de Periódicos da Coordenação de Aperfeiçoamento de Pessoal de Nível Superior (Capes), conteúdo assinado pela Unicamp. O acervo constituído, data de maio de 2015, em que identificamos setenta trabalhos, que foram resumidos no modelo tipo REDUC, que evidenciam as características principais dos trabalhos (FUNDAÇÃO CARLOS CHAGAS, 1997) e posteriormente analisados segundo suas tendências teóricometodológicas.

\section{Resultados e Discussão}

O trabalho situa-se em um quadro teórico que articula modos de compreensão acerca das políticas curriculares para o Ensino Médio e aspectos relacionados à formação de professores com foco na noção de identidade docente a partir da disciplina escolar.

Como resultados, identificamos que as produções acadêmicas levantadas se dividem entre pesquisas bibliográficas, documentais e de investigação prática, quais se sobrepõem as pesquisas de políticas públicas. Bem como a área de humanas é o principal campo de conhecimento presente.

Dentre os conteúdos de maior recorrência nos trabalhos levantados estão: a formação inicial docente, identidade profissional de cursos específicos, questões de gênero e educação especial.

Todas as pesquisas que tratam da temática disciplina escolar aborda o tema, por meio de uma disciplina específica, seja da educação básica, como Educação Física e Geografia ou de cursos superiores a exemplo a disciplina de Libras nos cursos de Fonoaudiologia.

Por fim, dentre as setenta produções acadêmicas levantadas, apenas sete delas relacionam a constituição da identidade docente, a partir da natureza de uma disciplina escolar específica.

\section{Conclusão}

Para Petrucci-Rosa (2010), o trabalho com identidades docentes, na relação com as disciplinas escolares, mobiliza distintos discursos, que estão relacionados com o contexto das políticas curriculares oficiais e as experiências profissionais, que perpassam pelas formações acadêmicas e também, pelas histórias de vida de cada professor, que se inicia no momento da escolha de sua profissão. Neste cenário, a partir da cartografia das produções acadêmicas realizada, evidenciamos a demanda por trabalhos que aprofundem a temática identidade docente e disciplina escolar.

\section{Agradecimentos}

\section{Projeto financiado pela CNPq.}

\footnotetext{
${ }^{1}$ FUNDAÇÃO CARLOS CHAGAS, Resumos analíticos em educação, São Paulo: FCC/DPE, 1997.

${ }_{2}^{2}$ PETRUCCI-ROSA, Maria Inês. Projeto de pesquisa: Práticas curriculares e Disciplinas Escolares: uma cartografia da produção acadêmica brasileira. PIBIC- CNPq. 2015.

${ }^{3}$ PETRUCCI-ROSA, Maria Inês. Formação docente, identidade profissional e a disciplina escolar: práticas curriculares no ensino médio. Revista: Zetetiké FE - Unicamp, v. 18, n. temático, 2010.
} 